\title{
Pembuatan Ekstrak Rhizophora mucronata Lamk. Sebagai Bahan Baku Inhibitor Korosi Skala Lab dan Skala Aplikasi
}

\author{
${ }^{(1)}$ Wajilan, ${ }^{(2) *}$ Andrian Fernandes, ${ }^{(1)}$ Arif Wahyudianto \\ ${ }^{(1)}$ Politeknik Negeri Samarinda, Jl. DR Ciptomangunkusumo, Kampus Gunung Lipan, Samarinda, \\ Kalimantan Timur \\ (2) Babes Litbang Ekosistem Hutan Dipterokarpa, Jl. A W Syahrani no. 68, Sempaja, Samarinda, \\ Kalimantan Timur \\ *Email: af.andrian.fernandes@gmail.com \\ Diterima: 28-12-2020, Disetujui: 29-05-2021, Diterbitkan: 30-05-2021
}

\begin{abstract}
The preparation of inhibitors in the form of concentrated extracts from organic materials on a labscale has been widely carried out, but experiments on a larger application scale are rarely carried out. Organic materials for making concentrated extracts can use mangrove leaves (Rhizophora mucronata Lamk.) which are found in many mangrove areas. This research aimed to compare the process of making the inhibitor in the form of a concentrated extract from the lab-scale mangrove leaves with a larger application scale related to the concentration-time, the electrical power used, physical properties (specific gravity and color properties), and phytochemical properties (alkaloid, flavonoid, saponin and tannin) of the concentrated extract. On a lab scale, 500 grams of dry mangrove leaves bini, dissolved in $500 \mathrm{ml}$ of $96 \%$ ethanol, after 2 days the filtrate is filtered and concentrated to $10 \mathrm{ml}$ using a rotary evaporator. The application scale is 20 times larger than the labscale and the concentration process uses a fan. The results showed that the process of making $10 \mathrm{ml}$ of lab-scale concentrated extract using a rotary evaporator took 4 hours, consuming $10.4 \mathrm{kWh}$ of electrical power. Concentrated extract has a specific gravity of 0.958 and color properties $L *=2.8$, $a^{*}=6.6$ and $b^{*}=3.2$. While the process of making $200 \mathrm{ml}$ of the concentrated extract on a larger application scale using a fan takes 72 hours, consuming an electric power of $3.6 \mathrm{kWh}$. Concentrated extract has a specific gravity of 0.965 and color properties $L^{*}=6.8, a *=17.4$ and $b *=8.8$. Both extraction methods have the same phytochemical components, i.e. flavonoid, saponin and tannin.
\end{abstract}

Keywords: inhibitor, concentrated extract, Rhizopora mucronata Lamk., lab scale, aplication scale

\begin{abstract}
ABSTRAK
Pembuatan inhibitor dalam bentuk ekstrak pekat dari bahan organik pada skala lab telah banyak dilakukan, namun percobaan dalam skala aplikasi yang lebih besar jarang dilakukan. Bahan organik pembuatan ekstrak pekat dapat menggunakan daun bakau (Rhizopora mucronata Lamk.) banyak ditemukan di daerah mangrove. Penelitian ini bertujuan untuk membandingkan proses pembuatan inhibitor berupa ekstrak pekat dari daun bakau skala lab dengan skala aplikasi yang lebih besar terkait waktu pemekatan, daya listrik yang digunakan, sifat fisik (berat jenis dan sifat warna), sifat fitokimia (alkaloid, flavonoid, saponin dan tannin) dari ekstrak pekat yang dihasilkan. Pada skala lab, 500 gram daun kering bakau, dilarutkan dalam $500 \mathrm{ml}$ etanol $96 \%$, setelah 2 hari filtrate disaring dan dipekatkan hingga menjadi $10 \mathrm{ml}$ menggunakan rotary evaporator. Pada skala aplikasi 20 kali lebih besar dari skala lab dan proses pemekatan menggunakan kipas angin. Hasil penelitian menunjukkan bahwa proses pembuatan $10 \mathrm{ml}$ ekstrak pekat skala lab menggunakan rotary evaporator memerlukan waktu 4 jam, dengan menghabiskan daya listrik sebesar 10,4 KWH. Ekstrak pekat memiliki berat jenis 0,958 dan sifat warna $\mathrm{L}^{*}=2,8, \mathrm{a}^{*}=6,6$ dan $\mathrm{b}^{*}=3,2$. Sedangkan proses pembuatan $200 \mathrm{ml}$ ekstrak pekat skala aplikasi yang lebih besar yang menggunakan kipas angin memerlukan waktu 72 jam, dengan menghabiskan daya listrik sebesar 3,6 KWH. Ekstrak pekat memiliki berat jenis 0,965 dan sifat warna $\mathrm{L}^{*}=6,8, \mathrm{a}^{*}=17,4$ dan $\mathrm{b}^{*}=8,8$. Kedua cara ekstraksi memiliki komponen fitokimia yang sama, yaitu flavonoid, saponin dan tannin.
\end{abstract}

Kata Kunci: inhibitor, ekstrak pekat, Rhizophora mucronata Lamk., skala lab, skala aplikasi 


\section{Pendahuluan}

Selama bertahun-tahun, banyak upaya telah dilakukan untuk menemukan inhibitor korosi yang ramah lingkungan (Rani \& Basu, 2012). Inhibitor korosi ramah lingkungan disebut juga inhibitor korosi hijau karena sebagian besar inhibitor berasal dari tumbuhan (Salhi, Bouyanzer, Chetouani, El Ouariachi, Zarrouk, Hammouti, Desjobert, \& Costa, 2017).

Salah satu tumbuhan yang banyak ditemukan di daerah pesisir adalah bakau (Rhizopora mucronata Lamk.). Bakau (R. mucronata Lamk.) memiliki buah yang lebih panjang dibandingkan dengan bakau laki. Bagian yang digunakan sebagai bahan baku inhibitor (ekstrak pekat) adalah daun. Daun bakau sesuai dengan syarat bahan inhibitor alami. Bahan baku pembuatan inhibitor alami harus mudah didapat, harus murah, terbiodegradasi secara alami bila sudah tidak digunakan (Sanni, Fayomi, \& Popoola, 2019). Ekstrak yang akan digunakan sebagai inhibitor alami juga haruns mengandung kelompok fitokimia yang berfungsi sebagai senyawa inhibitor, seperti alkaloid, flavonoid, saponin dan tannin.

Pembuatan inhibitor berupa ekstrak pekat yang ramah lingkungan tidak hanya diaplikasikan pada skala lab, namun harus dapat diaplikasikan pada skala aplikasi yang lebih besar dengan memperhatikan ketersediaan bahan dan cara pembuatan yang mudah pada skala komersial (Ogunleye, Arinkoola, Eletta, Agbeda, Osho, Morakinyo, \& Hamed., 2020). Pengembangan pembuatan inhibitor berupa ekstrak pekat dari skala lab menjadi skala aplikasi yang lebih besar dengan cara yang efisien untuk menggantikan bahan kimia inhibitor konvensional (Chigondo, \& Chigondo, 2016).

Selama ini riset pembuatan inhibitor sering dilakukan skala lab menggunakan prosedur rumit dan alat teknologi tinggi, misalnya untuk pemekatan ekstrak menggunakan rotary evaporator dengan harga investasi alat yang mahal dan konsumsi daya listrik yang besar. Sedangkan percobaan pembuatan inhibitor skala aplikasi yang lebih besar jarang dilakukan. Percobaan pembuatan inhibitor skala aplikasi yang lebih besar dapat menggunakan alat yang mudah digunakan oleh masyarakat umum dengan harga investasi yang lebih murah dengan daya listrik yang lebih kecil, misalnya menggunakan kipas angin. Penelitian bertujuan untuk membandingkan proses pembuatan inhibitor berupa ekstrak pekat dari daun bakau (R. mucronata Lamk.) skala lab menggunakan rotary evaporator dan skala aplikasi yang lebih besar menggunakan kipas angin, terkait waktu pemekatan, daya listrik yang digunakan, sifat fisik (berat jenis dan sifat warna) dan sifat fitokimia (alkaloid, flavonoid, saponin dan tannin) ekstrak pekat yang dihasilkan.

\section{Bahan dan Metode}

\subsection{Alat dan Bahan}

Alat yang digunakan pada pembuatan inhibitor berupa ekstrak pekat pada skala lab adalah erelnmeyer 1 liter, kertas saring, beker glass, rotary evaporator, gelas ukur, beker glass. Alat yang digunakan pada skala aplikasi yang lebih besar adalah botol, kertas saring, kipas angin, nampan, gelas ukur. Bahan yang digunakan adalah daun bakau ( $R$. mucronata Lamk.) dan etanol 96\%. Daun bakau ( $R$. mucronata Lamk.) diperoleh dari hutan bakau Balikpapan

\subsection{Metode Penelitian}

Pada skala lab, 500 gram daun kering bakau ( $R$. mucronata Lamk.), dilarutkan dalam $500 \mathrm{ml}$ etanol $96 \%$, setelah 2 hari filtrate disaring dan dipekatkan hingga menjadi $10 \mathrm{ml}$ menggunakan rotary evaporator. Waktu penggunaan rotary evaporator dicatat dan dihitung daya listrik yang digunakan untuk proses pemekatan yang dilakukan.

Pada skala aplikasi yang lebih besar, $10 \mathrm{~kg}$ daun kering bakau ( $R$. mucronata Lamk.), dilarutkan dalam 10 liter etanol 96\%, setelah 2 hari filtrate disaring dan dipekatkan hingga 200 $\mathrm{ml}$. Proses pemekatan menggunakan kipas angin untuk menguapkan etanol. Waktu penggunaan kipas angin dicatan dan dihitung daya listrik yang digunakan untuk proses pemekatan yang dilakukan.

Ekstrak pekat dari proses lab dan proses aplikasi yang diperoleh, selanjutnya diuji kualitas fisiknya, meliputi berat jenis dan sifat warnanya. Pengujian berat jenis ekstrak pekat menggunakan metode pycnometer (Morguette, Bigotto, Varella, Andriani, Spoladori, Pereira, Andrare, Lancheros, Nakamura, Arakawa, 
Bruschi, Tomaz, Lonni, Kerbauy, Tavares, Yamauchi, \& Ogatta, 2019), dan analisa warna ekstrak pekat menggunakan computer vision analysis (Riquelme, \& Matiacevich, 2017).

Untuk mengetahui kesamaan kandungan ekstrak, dilakukan uji sifat fitokimia pada hasil ekstrak hasil skala lab dan skala aplikasi yang lebih besar. Pengujian fitokimia meliputi alkaloid, flavonoid, saponin dan tannin. Penambahan beberapa tetes larutan dragendorff pada $3 \mathrm{ml}$ ekstrak pekat menghasilkan warna merah-jingga, menunjukkan adanya alkaloid (Oeung, Nov, Ung, Roum, Yin, \& Keo, 2017). Penambahan $1 \mathrm{ml} 1 \%$ ammonium pada $1 \mathrm{ml}$ ekstrak pekat menunjukkan adanya flavonoid setelah dikocok membentuk warna kuning (Oeung, Nov, Ung, Roum, Yin, \& Keo, 2017). Penambahan $1 \mathrm{ml}$ ekstrak pekat pada $20 \mathrm{ml}$ aquadest menunjukkan adanya saponin setelah dikocok akan menghasilkan buih (Surya, \& Hari, 2017). Penambahan $1 \mathrm{ml} \mathrm{NaOH} 1 \%$ pada $5 \mathrm{ml}$ ekstrak pekat menghasilkan endapan berwarna kuning-merah menunjukkan adanya tannin (Keo, Meng, Oeung, Nov, Lon, Vichet, Va, Sourn, \& Chea, 2017).

\section{Hasil dan Pembahasan}

\section{Perbandingan Pemuatan Inhibitor Skala Lab dan Skala Aplikasi yang Lebih Besar}

Berdasarkan hasil percobaan yang diperoleh tentang pembuatan ekstrak pekat untuk inhibitor korosi pada skala lab dan skala yang lebih besar dapat dilihat pada tabel 1 berikut ini.

Tabel 1. Perbandingan pembuatan inhibitor skala lab dan skala yang lebih besar

\begin{tabular}{ccc}
\hline Parameter & Skala lab & $\begin{array}{c}\text { Skala aplikasi yang } \\
\text { lebih besar }\end{array}$ \\
\hline $\begin{array}{c}\text { Wadah } \\
\text { ekstraksi }\end{array}$ & Erlenmeyer & Botol \\
\hline Kapasitas & $500 \mathrm{ml}$ & 10 liter \\
\hline $\begin{array}{c}\text { Hasil ekstrak } \\
\text { pekat }\end{array}$ & $10 \mathrm{ml}$ & $200 \mathrm{ml}$ \\
\hline Alat pemekatan & $\begin{array}{c}\text { Rotary } \\
\text { evaporator }\end{array}$ & Kipas angin \\
\hline Recovery & $\begin{array}{c}\text { Etanol } \\
\text { dapat } \\
\text { pelarut } \\
\text { kembali }\end{array}$ & $\begin{array}{c}\text { Etanol menguap ke } \\
\text { udara }\end{array}$ \\
\hline
\end{tabular}

Salah satu cara ekstraksi yang mudah dan memerlukan energi yang rendah dengan cara merendam bahan dalam pelarut tertentu, seperti air, etanol, chloroform dan berbagai pelarut lainnya (Sun, Wu, Wang, \& Zhang, 2015). Etanol merupakan pelarut terbaik untuk proses ekstraksi, mudah diuapkan untuk meningkatkan kemurnian hasil ekstraksi dan aman digunakan (Bahrin, Muhammad, Abdullah, Talip, Jusoh, \& Theng, 2018). Pelarut yang digunakan adalah etanol teknis $96 \%$. Semakin tinggi konsentrasi eatnol maka waktu penguapan pelarut semakin cepat (Gurrala, Katre, Balusamy, Banerjee, \& Sahu, 2019). Saat ini di pasaran, etanol teknis yang dijual memiliki konsentrasi tertinggi $96 \%$.

Untuk memekatkan hasil ekstraksi dari pelarut, dalam hal ini etanol $96 \%$, proses evaporasi merupakan pilihan yang tepat (Innocenzi, Malfatti, Costacurta, \& Kidchob, 2008). Pada rotary evaporator, pelarut terpisah dari larutan ekstrak akibat adanya proses vakum pada alat. Untuk mengeluarkan pelarut etanol dari larutan ekstrak dapat juga dilakukan dengan proses mempercepat aliran udara pada permukaan larutan ekstrak (Afanasyev, Orlova, \& Feoktistov, 2015). Hal ini dapat dilakukan menggunakan kipas angin. Semakin tinggi tekanan vakum pada evaporator dan semakin cepat aliran udara di permukaan larutan ekstrak maka proses penguapan etanol semakin cepat (Oh, \& Kato, 2017).

Target kepekatan dari skala lab dan skala aplikasi yang lebih besar adalah sama. Pada skala aplikasi yang lebih besar merupakan dua puluh kali lebih besar dibandingkan dengan skala lab. Artinya, bila target skala lab diperoleh $10 \mathrm{ml}$ ekstrak pekat, maka pada skala aplikasi yang lebih besar ditargetkan memperoleh $200 \mathrm{ml}$ ekstrak pekat. Kebutuhan listrik dan lama waktu pembuatan esktrak pekat dapat dilihat pada tabel 2 berikut ini.

Tabel 2. Perbandingan pembuatan inhibitor skala lab dan skala yang lebih besar

\begin{tabular}{ccc}
\hline Parameter & Skala lab & $\begin{array}{c}\text { Skala } \\
\text { aplikasi yang } \\
\text { lebih besar }\end{array}$ \\
\hline $\begin{array}{c}\text { Alat } \\
\text { pemekatan }\end{array}$ & Rotary evaporator & Kipas angin \\
\hline $\begin{array}{c}\text { Bagian yang } \\
\text { menggunakan } \\
\text { listrik }\end{array}$ & $\begin{array}{c}\text { 2 bagian, yaitu } \\
\text { bagian pemanas } \\
\text { labu ekstraksi dan } \\
\text { bagian pemutar labu } \\
\text { ekstraksi }\end{array}$ & $\begin{array}{c}\text { yaitu bagian } \\
\text { motor } \\
\text { pemutar bilah } \\
\text { kipas angin }\end{array}$ \\
\hline $\begin{array}{c}\text { Kebutuhan } \\
\text { daya listrik }\end{array}$ & $\begin{array}{c}\text { 2 bagian @ 1300 } \\
\text { watt }\end{array}$ & $\begin{array}{c}\text { bagian @ 50 } \\
\text { watt }\end{array}$ \\
\hline Waktu & 4 jam & 72 jam \\
\hline
\end{tabular}




\begin{tabular}{ccc}
\hline ekstraksi & & \\
\hline $\begin{array}{c}\text { Daya listrik } \\
\text { selama } \\
\text { pemekatan }\end{array}$ & $\begin{array}{c}4 \text { jam x 2 bagian x } \\
1300 \text { watt }\end{array}$ & $\begin{array}{c}72 \text { jam x 1 } \\
\text { bagian x 50 } \\
\text { watt }\end{array}$ \\
\hline $\begin{array}{c}\text { Total daya } \\
\text { listrik }\end{array}$ & $10,4 \mathrm{KWh}$ & $3,6 \mathrm{KWh}$ \\
\hline
\end{tabular}

Pada skala lab, 500 gram daun kering bakau (R. mucronata Lamk.), dilarutkan dalam $500 \mathrm{ml}$ etanol $96 \%$, setelah 2 hari filtrat disaring dan dipekatkan hingga menjadi $10 \mathrm{ml}$ menggunakan rotary evaporator. Rotary evaporator kapasitas 1 liter memiliki 2 bagian yang menggunakan daya listrik, yaitu bagian pemanas labu ekstraksi dan bagian pemutar labu ekstraksi. Bagian pemanas labu berfungsi untuk memanaskan pelarut ekstrak menjadi uap, sedangkan pemutar labu ekstraksi berfungsi memutar labu agar tidak terjadi penggumpalan filtrat pada bagian tertentu selama pemekatan. Karena memiliki 2 bagian yang menggunakan listrik, maka konsumsi daya yang lebih tinggi yaitu sekitar 2 x 1300 watt). Waktu yang dibutuhkan untuk memekatkan filtrate ekstrak menjadi $10 \mathrm{ml}$ sekitar 4 jam. Maka daya listrik yang dibutuhkan rotary evaporator adalah 4 jam x 2 x 1300 watt, yaitu sebesar 10.400 watt atau 10,4 KWH.

Pada skala aplikasi yang lebih besar, 10 $\mathrm{kg}$ daun kering bakau (R. mucronata Lamk.), dilarutkan dalam 10 liter etanol $96 \%$, setelah 2 hari filtrate disaring dan dipekatkan hingga $200 \mathrm{ml}$. Proses pemekatan menggunakan kipas angin untuk menguapkan etanol. Kipas angin yang digunakan memiliki konsumsi daya 50 watt dengan bilah $40 \mathrm{~cm}$. Waktu yang dibutuhkan untuk memekatkan filtrate esktrak menjadi $200 \mathrm{ml}$ sekitar 3 hari atau 72 jam. Maka daya listrik yang dibutuhkan kipas angina adalah $72 \times 50$ watt, yaitu sebesar 3.600 watt atau 3,6 KWH.

\section{Perbandingan Sifat Fisik Inhibitor Skala Lab dan Skala Aplikasi Lebih Besar}

Perbandingan sifat fisik (berat jenis dan sifat warna) inhibitor yang dibuat dapat dilihat pada tabel 3 berikut ini.

Tabel 3. Perbandingan sifat fisik inhibitor skala lab dan skala aplikasi yang lebih besar

\begin{tabular}{ccc}
\hline Parameter & Skala lab & $\begin{array}{c}\text { Skala aplikasi } \\
\text { yang lebih besar }\end{array}$ \\
\hline Berat jenis & 0,958 & 0,965 \\
\hline Sifat warna & & \\
\hline L $^{*}$ (lightness) & 2,8 & 6,8 \\
\hline
\end{tabular}

\begin{tabular}{ccc}
\hline $\begin{array}{c}\mathrm{a}^{*} \text { (red-green } \\
\text { axis) }\end{array}$ & 6,6 & 17,4 \\
\hline \begin{tabular}{c}
$\mathrm{b}^{*}\left(\begin{array}{c}\text { yellow-blue } \\
\text { axis) }\end{array}\right.$ \\
\hline
\end{tabular} & 3,2 & 8,8 \\
\hline
\end{tabular}

Hasil pengukuran berat jenis menggunakan metode pycnometer, menunjukkan bahwa ekstrak pekat skala lab memiliki berat jenis 0,958 . Sedangkan ekstrak pekat dari aplikasi yang lebih besar memiliki berat jenis 0,965 .

Pada pengukuran sifat warna, mata manusia bila digunakan untuk mengamati sifat warna cenderung subyektif dan bias, sehingga digunakan digital image processing untuk menghasilkan unsur warna yang lebih detil (Segura, Salvadori, \& Goni, 2017). Sifat warna L* bernilai 0 menunjukkan bahwa benda tidak memiliki pantulan cahaya atau berwarna hitam, bila $L^{*}=100$ menunjukkan bahwa benda memantulkan cahaya atau berwarna putih, sedangkan $\mathrm{a}^{*}$ bernilai positif menunjukkan bahwa benda cenderung berwarna merah dan $\mathrm{b}^{*}$ bernilai positif menunjukkan bahwa benda cenderung berwarna kuning (Horvath, 2016). Artinya berdasarkan nilai warna, esktrak pekat hasil skala lab menunjukkan warna yang lebih gelap (nilai $\mathrm{L}^{*}=2,8, \mathrm{a}^{*}=6,6$ dan $\mathrm{b}^{*}=3,2$ yang memiliki nilai lebih kecil) dibandingkan dengan ekstrak pekat hasil proses aplikasi yang lebih besar (nilai $\mathrm{L}^{*}=6,8, \mathrm{a}^{*}=17,4$ dan $\mathrm{b}^{*}=$ $8,8)$.

\section{Perbandingan Sifat Fitokimia dari Inhibitor Skala Lab dan Skala Aplikasi yang Lebih Besar}

Perbandingan sifat fitokimia inhibitor yang dibuat dapat dilihat pada tabel 4 berikut ini.

Tabel 4. Perbandingan sifat fitokimia inhibitor skala lab dan skala aplikasi yang lebih besar

\begin{tabular}{|c|c|c|}
\hline $\begin{array}{l}\text { Komponen } \\
\text { fitokimia }\end{array}$ & Skala lab & Skala aplikasi \\
\hline Alkaloid & - & - \\
\hline Flavonoid & + & + \\
\hline Saponin & + & + \\
\hline Tannin & + & + \\
\hline Keterangan : & $\begin{array}{l}: \text { mengand } \\
: \text { tidak me }\end{array}$ & $\begin{array}{l}\text { enyawa uji } \\
\text { ung senyawa uji }\end{array}$ \\
\hline
\end{tabular}

Dari hasil uji fitokimia menunjukkan bahwa komponen fitokimia dari kedua hasil pembuatan adalah sama, baik skala lab maupun skala aplikasi. Kedua cara pembuatan inhibitor 
tidak mengandung alkaloid. Kedua cara ekstraksi mengandung flavonoid, saponin dan tannin yang berpotensi sebagai inhibitor korosi pada logam. Kelompok senyawa flavonoid dapat berfungsi sebagai inhibitor korosi pada baja ringan (Ikeuba, Ita, Etiuma, Bassey, Ugi, Kporokpo, \& Chemistry, 2015) dan pada tembaga (Al-Qudah, 2011). Kelompok saponin dapat berfungsi sebagai inhibitor korosi pada baja ringan (Singh, Ebenso, \& Quraishi, 2012). Kelompok tannin dapat berfungsi sebagai inhinitor korosi pada baja ringan (Okafor, Ebiekpe, Azike, Egbung, Brisibe, \& Ebenso, 2012), tembaga dan berbagai alloy logam lainnya (Kusmierek, \& Chrzescijanska, 2015).

\section{Kesimpulan}

Proses pembuatan ekstrak pekat skala lab menggunakan rotary evaporator. Untuk menghasilkan $10 \mathrm{ml}$ ekstrak pekat dari 500 gram daun kering bakau ( $R$. mucronata Lamk.), dilarutkan dalam $500 \mathrm{ml}$ etanol 96\% memerlukan waktu 4 jam, dengan menghabiskan daya listrik sebesar 10,4 KWH. Ekstrak pekat memiliki berat jenis 0,958 dan sifat warna $L^{*}=2,8, a^{*}=6,6$ dan $b^{*}=3,2$.

Proses pembuatan ekstrak pekat skala aplikasi yang lebih besar dapat menggunakan kipas angin. Untuk menghasilkan $200 \mathrm{ml}$ ekstrak pekat dari $10 \mathrm{~kg}$ daun kering bakau $(R$. mucronata Lamk.), dilarutkan dalam 10 liter etanol 96\% memerlukan waktu 72 jam, dengan menghabiskan daya listrik sebesar 3,6 KWH. Ekstrak pekat memiliki berat jenis 0,965 dan sifat warna $L^{*}=6,8, a^{*}=17,4$ dan $b^{*}=8,8$.

Berdasarkan hail uji fitokimia, proses pembuatan inhibitor skala lab dan skala aplikasi yang lebih besar memiliki komponen fitokimia yang sama, yaitu flavonoid, saponin dan tannin.

\section{Ucapan Terima Kasih}

Ucapan terima kasih diberikan kepada Prof. Dr. Ganis Lukmandaru yang telah membimbing dalam proses ekstraksi skala lab.

\section{Daftar Pustaka}

Afanasyev, I., Orlova, E., \& Feoktistov, D. (2015). Evaporation of Stationary Alcohol Layer in Minichannel Under Air Flow. EPJ Web of Conferences. 82. Doi: 10.1051/epjconf/20158201054.
Al-Qudah, M. A. (2011). Inhibition of copper corrosion by flavonoids in nitric acid. E-Journal of Chemistry, 8(1), 326-332. https://doi.org/10.1155/2011/543498.

Bahrin, N., N. Muhammad, N. Abdullah, B. Hj. A. Talip, S. Jusoh, \& S. W. Theng. (2018). Effect of Processing Temperature on Antioxidant Activity of Ficus carica Leaves Extract. Journal of Science and technology. 10 (2), pp. 99-103.

Chigondo, M., \& F. Chigondo. (2016). Recent Natural Corrosion Inhibitors for Mild Stell: An Overview. Journal of Chemistry. Doi: 10.1155/2016/6208937.

Gurrala, P., K. Katre, P., Balusamy, S., Banerjee, S., \& Sahu, K. C. (2019). Evaporation of Ethanol-water Droplet at Different Substrate temperatures and Compositions. International Journal of Heat and Mass Transfer. 145. Doi: 10.1016/j.ijheatmasstransfer.2019.118770

Horvath, Z. H. (2016). The effect of Storage on the Colour of Paprika Powders with Added Oleoresin. Acta Univ. sapientiae Alimentaria, 9, pp. 50-59.

Ikeuba, A. I., Ita, B. I., Etiuma, R. A., Bassey, V. M., Ugi, B. U., Kporokpo, E. B., \& Chemistry, A. (2015). Green Corrosion Inhibitors for Mild Steel in $\mathrm{H}_{2} \mathrm{SO}_{4}$ Solution: Flavonoids of Gongronema latifolium. Chemical and Process Engineering Research, 34, 1-10.

Innocenzi, P., Malfatti, L., Costacurta, S., \& Kidchob, T. (2008). Evaporation of Ethanol and Ethanol-Water Mixtures Studied by Time-resolved Infrared Spectroscopy. J. Phys. Chem. A. 112, pp. 6512-6516.

Keo, S., Meng, C., Oeung, S., Nov, V., Lon, S. A., Vichet, T., Va, T., Sourn, M., \& Chea, S. (2017). Preliminary Phytochemical Screening of Selected Medicinal Plants of Cambodia. Asian Journal of Pharmacognosy; 1 (4), 1623.

Kusmierek, E., \& Chrzescijanska, E. (2015). Tannic acid as corrosion inhibitor for metals and alloys. Materials and Corrosion, 66(2), 169- 
174.https://doi.org/10.1002/maco.201 307277 .

Morguette, A. E. B., B. G., Bigotto, R. L., Varella, G. M., Andriani, L. F. A., Spoladori, P. M. L., Pereira, F. G., Andrare, C. A. C., Lancheros, C. V., Nakamura, N. S., Arakawa, M. L., Bruschi, J. C., Tomaz, A. A. S. G., Lonni, G., Kerbauy, E. R., Tavares, L. M., Yamauchi, \& S. F. Y. Ogatta, (2019). Hydrogel Containing Oleoresin from Copaifera officinalis Presents Antibacterial Activity Against Streptococcus agalactiae. Frontiers in Microbiology, $10 . \quad$ doi: 10.3389/fmicb.2019.02806.

Oeung, S., Nov, V., Ung, H., Roum, K., Yin, V., \& Keo, S. (2017). Phytochemical analysis of different extracts of leaves of Nicotiana tabacum L. of Cambodia. Asian Journal of Pharmacognosy Research. 1(3), pp 18-26.

Oh, W., \& Kato, S. (2017). Study on the Effect of Evaporation and Condensation on the Underfloor Space of Japanese Detached House Using CFD Analysis. Energies. Doi: 10.3390/en10060789.

Ogunleye, O. O., A. O. Arinkoola, O. A. Eletta, O. O. Agbeda, Y. A. Osho, A. F. Morakinyo, \& J. O. Hamed. (2020). Green Corrosion Inhibition and Adsorption Characteristics of Luffa cylindrical Leaf Extract on Mild Steel in Hydrochloric Acid Environment. Heliyon. Doi: 10.1016/j.heliyon.2020.e03205.

Okafor, P. C., Ebiekpe, V. E., Azike, C. F., Egbung, G. E., Brisibe, E. A., \& Ebenso, E. E. (2012). Inhibitory action of artemisia annua extracts and artemisinin on the corrosion of mild steel in HOsolution. International Journal of Corrosion, 2012. https://doi.org/10.1155/2012/768729.

Rani, B. E. A., \& Basu, B. B. J. (2012). Green Inhibitors for Corrosion Protection of Metals and Alloys: an Overview. International Journal of Corrosion, doi: $10.1155 / 2012 / 380217$.

Riquelme, N., \& S.Matiacevich. (2017). Characterization and Evaluation of Some Properties of Oleoresin from Capsicum annuum var. cacho de cabra. Journal of Food, 15(3), pp. 344-351.

Salhi, A., Bouyanzer, A., Chetouani, A., El Ouariachi, E., Zarrouk, A., Hammouti, B., Desjobert, J.M., \& Costa, J. (2017). Chemical Composotion, Antioxidant and Corrosion Activities of Mentha suaveolens, JMES, 8(5), pp. 1718-1728.

Sanni, O., O. S. I. Fayomi, \& A. P. I. Popoola. (2019). Eco-friendly Inhibitors for Corrosion Protection of Stainless Stell: an Overview. International Conference on Engineering for Sustainable World. Doi: 10.1088/1742-6596/1378/4/042047.

Segura, L. I., V. O., Salvadori, \& S. M. Goni. (2017). Characterization of Liquid food Colour from Digital Images. International Journal of Food Properties, 20, S1, pp. S467-S477.

Singh, A., Ebenso, E. E., \& Quraishi, M. A. (2012). Corrosion inhibition of carbon steel in $\mathrm{HCl}$ solution by some plant extracts. International Journal of Corrosion, 2012. https://doi.org/10.1155/2012/897430.

Sun, C., Z. Wu, Z. Wang, \& H. Zhang. (2015). Effect of Ethanol/water Solvent on Phenolic Profiles and Antioxidant Properties of Beijing Propolis Extracts. Evidence-Based Complementary and Alternative Medicine. Doi: $10.1155 / 2015 / 595393$.

Surya, S., \& Hari, N. (2017). Studies on preliminary phytochemical analysis of some true mangrove species in Kerala. International Journal of Research in Pharmacy and Pharmaceutical Sciences, 2(3), $15-17$. http://www.pharmacyjournal.in/archives/2 017/vol2/issue3/2-3-12. 